\title{
Simultaneous sulfur hexafluoride and nitrogen multiple-breath washout (MBW) to examine inherent differences in MBW outcomes
}

\author{
Katie J. Bayfield (10 ${ }^{1,2,3,4}$, Alex Horsley $\mathbb{1}^{5}$, Eric Alton ${ }^{1,2}$, Samantha Irving ${ }^{1,2}$, \\ Andrew Bush ${ }^{1,2}$ and Jane C. Davies ${ }^{1,2,3}$
}

\begin{abstract}
Affiliations: ${ }^{1}$ Imperial College London, London, UK. ${ }^{2}$ Royal Brompton and Harefield NHS Foundation Trust, London, UK. ${ }^{3}$ European Cystic Fibrosis Society Clinical Trials Network, Lung Clearance Index Core Facility, London, UK. "The Children's Hospital at Westmead, Sydney, Australia. ${ }^{5}$ Institute of Inflammation and repair, Education and Research centre, University of Manchester, University Hospital of South Manchester. Manchester, UK.
\end{abstract}

Correspondence: Katie J. Bayfield, The Children's Hospital at Westmead, Hawkesbury Road and Hainsworth Street, Locked bag 4001, Westmead 2145, Sydney, Australia. E-mail: katie.bayfieldahealth.nsw.gov.au

ABSTRACT Multiple-breath washout (MBW) can be performed with different gases (sulfur hexafluoride $\left(\mathrm{SF}_{6}\right)$ and nitrogen $\left(\mathrm{N}_{2}\right)$ ) and different devices, all of which give discrepant results. This study aimed to confirm previously reported differences and explore factors influencing discrepant results; equipment factors or the physical properties of gases used.

Methods: Healthy controls (HCs) and participants with cystic fibrosis (CF) completed MBW trials on two commercially available devices (Exhalyzer D $\left(\mathrm{N}_{2}\right)$ and Innocor $\left(\mathrm{SF}_{6}\right)$ ). Simultaneous washout of both gases at the same time on the commercial equipment and simultaneous washouts using a respiratory mass spectrometer (RMS) were completed in subsets. Primary outcomes were lung clearance index (LCI), breath number and time required to washout.

Results: Breath number was higher with $\mathrm{N}_{2}$ washout than $\mathrm{SF}_{6}$ in both $\mathrm{HCs}$ and patients with $\mathrm{CF}$, whether washouts were completed individually or simultaneously. The difference was greater in more advanced disease, largely caused by differences in the final part of the washout. Results from commercial devices were similar to those obtained with the RMS.

Conclusions: $\mathrm{N}_{2} \mathrm{MBW}$ results were higher than $\mathrm{SF}_{6} \mathrm{MBW}$, with some of the largest differences reported to date being observed. The biggest impact was at the end of the washout and this was even the case when gases were washed out simultaneously. $\mathrm{N}_{2}$ and $\mathrm{SF}_{6} \mathrm{MBW}$ results are inherently different and should be considered as independent measurements.

$@$ ERSpublications

Inherent differences in simultaneous $\mathrm{SF}_{6}$ and $\mathrm{N}_{2}$ washout on the mass spectrometer show why results are never comparable http://bit.ly/34k52Oo

Cite this article as: Bayfield KJ, Horsley A, Alton E, et al. Simultaneous sulfur hexafluoride and nitrogen multiple-breath washout (MBW) to examine inherent differences in MBW outcomes. ERJ Open Res 2019; 5: 00234-2018 [https://doi.org/10.1183/23120541.00234-2018].

This article has supplementary material available from openres.ersjournals.com

Received: 4 Dec 2018 | Accepted after revision: 27 Aug 2019

Copyright $\odot$ ERS 2019. This article is open access and distributed under the terms of the Creative Commons Attribution Non-Commercial Licence 4.0. 


\section{Introduction}

Lung clearance index (LCI) is increasingly used as an outcome measure in respiratory diseases such as cystic fibrosis (CF) [1-3]. Even in mild disease with well-preserved spirometry, LCI may be abnormal [4] indicating more sensitive detection of early disease. Continued improvements in CF health have necessitated more sensitive measures of lung function, therefore, understanding LCI is essential for both clinical practice and outcome measures for clinical trials [3].

LCI is derived from the multiple-breath washout (MBW) test and is calculated by dividing the cumulative expiratory volume over the washout test, by functional residual capacity (FRC). MBW can be performed either with a tracer gas such as sulfur hexafluoride $\left(\mathrm{SF}_{6}\right)$, or can use $100 \%$ oxygen to wash out resident nitrogen $\left(\mathrm{N}_{2}\right)$. The arbitrary end-point of 1/40th of the starting concentration $\left(\mathrm{LCI}_{2.5}\right)$ is the historical limit of the gas analysers to assess gas mixing and 1/20th $\left(\mathrm{LCI}_{5}\right)$ has been used to shorten the testing time by cutting the end of the washout period to increase feasibility in complex patients [5]. Different MBW technologies are in use; the gold standard is considered to be the respiratory mass spectrometer (RMS) [6]. This measures all gases directly but is expensive, nonportable and challenging to maintain. Alternative devices are now available but there are significant differences between MBW and LCI results when comparing washout of $\mathrm{N}_{2}$ and $\mathrm{SF}_{6}$ [7]. Currently, neither the 2013 European Respiratory Society (ERS)/ American Thoracic Society (ATS) MBW consensus statement, nor the 2018 pre-school MBW ATS statement recommends a specific device or washout gas over others $[6,8]$. It is only in infant testing that there is a clear mechanism for a discrepancy between test gases (change in breathing pattern and movement of $\mathrm{O}_{2}$ across the alveolar capillary membrane), leading to the suggestion that $\mathrm{SF}_{6}$ testing should be used in this cohort [9]. In CF and healthy control (HC) children (age 3-18 years) $\mathrm{N}_{2}$-derived LCI and FRC results were higher when compared with $\mathrm{SF}_{6}$ [7] but the mechanism behind this and the impact on result interpretation is still unclear. Possible explanations include equipment, physiological discrepancies between test gases [6] and dissolved $\mathrm{N}_{2}$ additionally contributing to the $\mathrm{N}_{2}$ washout [10].

We hypothesised that LCI would be intrinsically different for $\mathrm{N}_{2}$ than $\mathrm{SF}_{6}$ rather than related to equipment differences and that the results would not be interchangeable. We aimed to better understand the difference between the MBW results from $\mathrm{N}_{2}$ and $\mathrm{SF}_{6}$ in $\mathrm{HCs}$ and patients with $\mathrm{CF}$ with the following objectives:

1) Complete a comparison study with both paediatric and adult participants to confirm gas differences.

2) Complete a simultaneous washout on both devices to identify whether the washout trace was the same for both gases.

3) Complete exploratory testing using the RMS to identify possible equipment influences.

\section{Materials and methods}

Study design

Comparison of independent MBW devices

MBW measurements were performed in children and adults with CF and HCs. All of the participants (47 with $\mathrm{CF}$ and $42 \mathrm{HCs}$ ) took part in a straightforward comparison study of the Exhalyzer D (Eco Medics AG, Duernten, Switzerland), $\mathrm{N}_{2}$ washout $\left(\mathrm{N}_{2_{\mathrm{ExD}}}\right)$ [7] and the modified Innocor gas analyser (Innovision, Odense, Denmark) $\mathrm{SF}_{6}$ washout $\left(\mathrm{SF}_{6_{\mathrm{Inn}}}\right)$ [11]. At least two washout trials per participant were completed in all tests and sections of this study.

Simultaneous washout of $\mathrm{SF}_{6, \mathrm{ln}}$ and $\mathrm{N}_{2 \mathrm{ExD}}$

13 participants (5 with $\mathrm{CF}$ and $8 \mathrm{HCs}$ ) completed simultaneous washouts using the commercial equipment (Innocor and Exhalyzer D) attached in series. To minimise software bias, only end-tidal gas concentrations $\left(\mathrm{C}_{\mathrm{ET}}\right)$, breath number and time to the washout end-point were utilised for analysis.

\section{RMS: simultaneous washout}

$10 \mathrm{HCs}$ also completed simultaneous washouts using the commercial equipment attached in series with the RMS (AMIS 2000, Odense, Denmark). Again, only $\mathrm{C}_{\mathrm{ET}}$, breath number and time to washout were utilised for analysis. The study sections are summarised in figure 1 .

\section{Study subjects}

Subjects with CF, selected from routine clinic visits at the Royal Brompton Hospital, (RBH), UK, had a confirmed diagnosis [12] and were clinically stable (no pulmonary exacerbations and no irregular symptoms within 2 weeks). HC subjects with no history of airways disease or smoking were recruited from amongst patients' family members or staff allied to Imperial College, London or RBH. All subjects were over 5 years of age. 

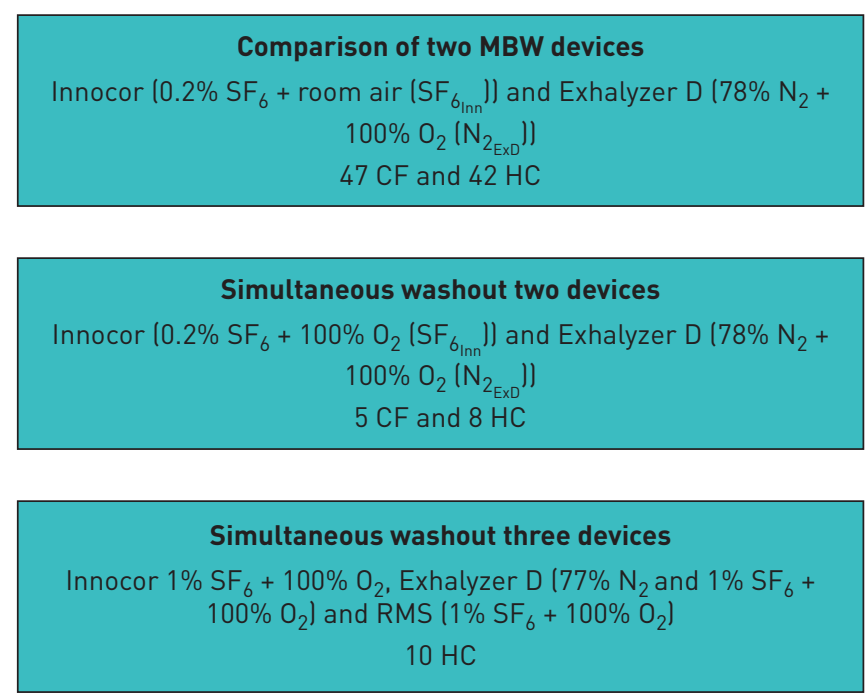

FIGURE 1 Flow diagram of overall study design, including each section, devices used and participants. MBW: multiple-breath washout; CF: cystic fibrosis; HC: healthy control; RMS: respiratory mass spectrometer.

Spirometry results were collected on patients with CF according to the ERS/ATS guidelines [13] using the Global Lung Initiative reference ranges [14].

This study was approved by the South East Coast Research Ethics Committee (number 10/H1101/69) and conducted in the clinical research facility at RBH between July 2015 and July 2017. Informed written consent and age-appropriate assent was obtained from each parent, guardian and/or participant respectively. Data were analysed as part of a $\mathrm{PhD}$ at Imperial College, London.

\section{Comparison of independent MBW devices}

Two MBW devices were used as previously reported; the $\mathrm{N}_{\mathrm{E}_{\mathrm{ExD}}}$ [7] and the $\mathrm{SF}_{\mathrm{G}_{\mathrm{In}},}$ [11]. In brief, patients with $\mathrm{CF}$ and $\mathrm{HCs}$ completed at least two MBW trials on each, during the same test occasion in a random order generated using a random number from an Excel (Microsoft, Washington, USA) spreadsheet. Analysis was performed on specialist software (custom-built offline analysis within Simplewashout for Inn (IGOR Pro, Wavemetrics, version 6.20B3) [15] or online using Spiroware (version 3.1.6.17312) for ExD). The washouts were compared at the conventional cut-off of $1 / 40$ th $\left(\mathrm{LCI}_{2.5}\right)$ of the starting end-tidal tracer gas concentration as well as the earlier 1/20th $\left(\mathrm{LCI}_{5}\right)$ cut-off. Further device set-up, specifications and comparisons can be found in the online supplement (OLS).

Simultaneous washout of $\mathrm{SF}_{6_{\text {Inn }}}$ and $\mathrm{N}_{2_{\mathrm{ExD}}}$

We undertook simultaneous, breath-by-breath comparisons of $\mathrm{SF}_{6}$ and $\mathrm{N}_{2}$ washouts. We attached the $\mathrm{SF}_{\mathrm{I}_{\mathrm{Inn}}}$ and $\mathrm{N}_{2_{\mathrm{ExD}}}$ in series, connecting flow meters using airtight plastic tubing (figure 2, total dead space $73.3 \mathrm{~mL}$ ). Tidal breathing of $0.2 \% \mathrm{SF}_{6}$ in wash-in was followed by washout of both $\mathrm{N}_{2}$ and $\mathrm{SF}_{6}$ with $100 \%$ $\mathrm{O}_{2}$. The washout was extended for $2 \mathrm{~min}$ beyond the usual washout end-point of $1 / 40$ th end-tidal gas concentration. To compare washout curves, gas signals were normalised to percentages and put onto a log scale. The curves were then matched to breath number and time to the $1 / 40$ th washout end-point for both $\mathrm{N}_{2}$ and $\mathrm{SF}_{6}$. To simplify the calculations, and to remove confounding variables such as gas signal alignment, sampling frequency and different apparatus dead spaces, we only looked at the $\mathrm{C}_{\mathrm{ET}}$. These were identified using the individual device $\mathrm{C}_{\mathrm{ET}}$ detection methods (see OLS).

\section{RMS: simultaneous washout}

To exclude the influence of device-specific differences in gas concentration measurement, an RMS sample line was fixed in place during the simultaneous washout set-up (figure 2), this also enabled comparison of all devices. A $1 \% \mathrm{SF}_{6}$ gas mix with $21 \% \mathrm{O}_{2}$ and balance $\mathrm{N}_{2}$ was utilised (BOC) so that all three devices could perform their washout protocols with $100 \% \mathrm{O}_{2}$ as the washout gas; $\mathrm{N}_{2}$ was measured by both RMS and $\mathrm{ExD}$, and $\mathrm{SF}_{6}$ was measured by RMS and Inn. Gas concentration for initial and final end-tidal gas concentrations was recorded. Breath number and washout time (1/40th) for the RMS was calculated by manually averaging the $\mathrm{C}_{\mathrm{ET}}$ for both $\mathrm{SF}_{6}$ and $\mathrm{N}_{2}$ using the $\mathrm{SW}$ software (see OLS). 


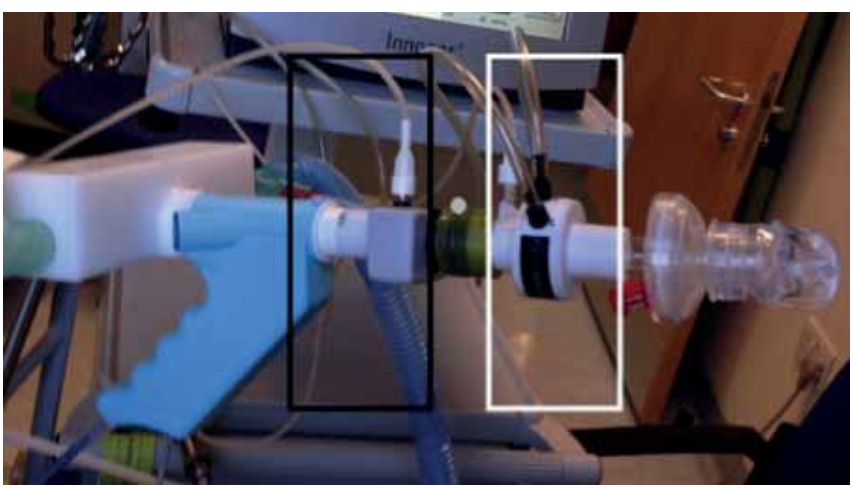

FIGURE 2 Flowmeters of the Exhalyzer D (nitrogen; black box) and Innocor (sulfur hexafluoride; white box) were attached in series with airtight plastic tubing. After calibrating each device with this set-up, the gas concentration and breath number during a multiple-breath washout test were then measured simultaneously. In some cases, a respiratory mass spectrometer (RMS) gas probe was also placed between the other devices (grey dot) to read gas concentrations directly using the RMS.

\section{Statistical analysis}

The study was not based on formal power calculations, as limited data were available using all techniques. Numbers were opportunistic with attempts to keep group sizes similar. Results were compared using paired $t$-tests and Bland-Altman analysis using GraphPad Prism 6 (GraphPad Software). Statistical significance was set at $\mathrm{p}<0.05$, Kolmogorov-Smirnov tests of normality were performed, $95 \%$ confidence intervals were displayed and Cohen d estimates of effect size were calculated.

\section{Results}

Comparison of independent MBW devices

$\mathrm{LCI}_{2.5}$ was significantly higher in patients with CF than $\mathrm{HCs}$ in both devices (table 1). LCI values were higher in $\mathrm{N}_{2}$ than $\mathrm{SF}_{6}$ in both groups; this difference was larger in patients with $\mathrm{CF}$ and increased relative to LCI. The Cohen $\mathrm{d}$ effect size was 1.46; the coefficients of variation were not different from each other (OLS table 3). The agreement between devices for $\mathrm{LCI}_{2.5}$ and $\mathrm{LCI}_{5}$ can be seen in figures 3 and 4 . There was a significant increased bias for $\mathrm{N}_{2}$ that was exaggerated with worse LCI. The difference between gases was decreased in $\mathrm{LCI}_{5}$ (LCI calculated at an earlier time point), showing the impact on the $\mathrm{N}_{2}$ washout was mostly at the tail end of the washout. $\mathrm{LCI}_{2.5}$ and $\mathrm{LCI}_{5}$ values obtained from $\mathrm{SF}_{6_{\mathrm{Inn}}}$ and $\mathrm{N}_{2 \mathrm{FxD}}$ were tightly correlated with forced expiratory volume in $1 \mathrm{~s}\left(\mathrm{FEV}_{1}\right)(\%) \mathrm{Z}$ score (OLS figures 1 and 2$)$ in patients with CF. The correlation slopes differed significantly in $\mathrm{LCI}_{2.5}$ and were steeper with $\mathrm{N}_{2_{\mathrm{ExD}}}$ but this was not the case with $\mathrm{LCI}_{5}$.

Simultaneous washout of $\mathrm{SF}_{6_{I n}}$ and $\mathrm{N}_{2_{\mathrm{ExD}}}$

Overall, eight HCs and five patients with CF (for full demographic data see OLS table 2) performed a simultaneous washout of $0.2 \% \mathrm{SF}_{6}$ and $\mathrm{N}_{2}$ using $100 \% \mathrm{O}_{2}$ with the $\mathrm{SF}_{6_{\mathrm{Inn}}}$ and $\mathrm{N}_{2_{\mathrm{ExD}}}$ attached in series. Clearance of test gas to 1/40th occurred after fewer breaths for $\mathrm{SF}_{6}$ than $\mathrm{N}_{2}$ in patients with $\mathrm{CF}(24.8 \pm 8.7$ versus $59.5 \pm 28.3$ breaths, $\mathrm{p}=0.063)$ and $\mathrm{HCs}(32.0 \pm 11.9$ versus $46.3 \pm 13.7$ breaths, $\mathrm{p}=0.001$; OLS table 3$)$.

Figure 5 shows the decline in tracer gases from one individual with CF; $\mathrm{SF}_{6}$ and $\mathrm{N}_{2}$ declined similarly at the beginning of the washout but separated beyond $\sim 20$ breaths. $\mathrm{SF}_{6}$ continued linearly downwards on the $\log$ scale, whereas $\mathrm{N}_{2}$ curved to a plateau from which it did not decline any further. In all patients, $\mathrm{SF}_{6}$ reached the end target first. $\mathrm{N}_{2}$ seemed to reach an average asymptote concentration of $1.26 \% \pm 0.09$ in $\mathrm{HCs}$ and $1.48 \% \pm 0.12$ in patients with $\mathrm{CF}$, whereas $\mathrm{SF}_{6}$ continued down to zero.

\section{RMS: simultaneous washout}

Overall, $10 \mathrm{HC}$ participants (for full demographic data see OLS table 2) performed simultaneous washout of both $\mathrm{SF}_{6}$ and $\mathrm{N}_{2}$ on the RMS; both of the other two devices were connected to allow a direct comparison. $\mathrm{SF}_{6}$ washout using the $\mathrm{RMS}$ is typically performed using $4 \% \mathrm{SF}_{6}$, and using $1 \% \mathrm{SF}_{6}$ led to an increased noise-to-signal ratio, particularly at the low $\mathrm{SF}_{6}$ concentrations found at the end of washout Despite the signal issues and small sample number, using RMS as the gas analysis tool, $\mathrm{N}_{2}$ was still slower and required a greater number of breaths to wash out than $\mathrm{SF}_{6}(34.5 \pm 12.4$ versus $45.8 \pm 19.1$ breaths, $\mathrm{p}=0.005)$. There were no differences in paired analysis of $\mathrm{SF}_{6}$ or $\mathrm{N}_{2}$ breaths to washout between the RMS and the Inn or ExD (RMS $\mathrm{N}_{2} 45.8 \pm 19.0$ versus $\mathrm{ExD} \mathrm{N}_{2} 46.8 \pm 19.4, \mathrm{p} \geqslant 0.05$ and $\mathrm{RMS} \mathrm{SF}_{6} 34.5 \pm 12.4$ versus Inn $\mathrm{SF}_{6} 36.8 \pm 13.9, \mathrm{p}>0.05$; OLS figures 3 and 4). 
TABLE 1 Comparison of multiple-breath washout devices, cystic fibrosis (CF) and healthy control (HC) demographics and lung clearance index (LCI) results

\begin{tabular}{|c|c|c|c|c|c|c|}
\hline & \multicolumn{3}{|c|}{$C F(n=47)$} & \multicolumn{3}{|c|}{$\mathrm{HC}(n=42)$} \\
\hline Age years & \multicolumn{3}{|c|}{$16.05(5.9-63.7)$} & \multicolumn{3}{|c|}{$24.32(5.7-56.1)$} \\
\hline $\begin{array}{l}\text { Weight kg, } \\
\text { Z-score }\end{array}$ & \multicolumn{3}{|c|}{$52.2 \pm 18,0.60 \pm 1.1$} & \multicolumn{3}{|c|}{$59.7 \pm 20.6,-0.27 \pm 1.2$} \\
\hline \multirow{2}{*}{$\begin{array}{l}\text { FEV }_{1} \% \text { pred, } \\
\text { Z-score }\end{array}$} & \multicolumn{3}{|c|}{$72.9 \pm 16.8,-2.29 \pm 1.43$} & \multicolumn{3}{|c|}{ Not done } \\
\hline & $\mathrm{SF}_{6_{\operatorname{lnn}}}$ & $\mathbf{N}_{\mathbf{E}_{\mathrm{ExD}}}$ & Difference $p$-value & $\mathrm{SF}_{6_{\operatorname{Inn}}}$ & $\mathbf{N}_{\mathbf{E}_{\mathrm{ExD}}}$ & Difference $\mathrm{p}$-value \\
\hline $\mathrm{LCl}_{2.5}$ & $\begin{array}{c}9.5 \pm 2.3(8.82 \text { to } \\
10.19)\end{array}$ & $\begin{array}{c}14.0 \pm 3.7(12.88 \text { to } \\
15.14)\end{array}$ & $\begin{array}{c}-4.5(-5.2 \text { to }-3.8) \\
p=<0.0001\end{array}$ & $\begin{array}{c}6.3 \pm 0.5 \\
(6.12-6.5)\end{array}$ & $\begin{array}{c}7.3 \pm 0.72 \\
(7.03-7.48)\end{array}$ & $\begin{array}{c}-0.9(-1.1 \text { to }-0.7) \\
p<0.0001\end{array}$ \\
\hline $\mathrm{LCl}_{5}$ & $\begin{array}{c}6.8 \pm 1.4(6.38 \text { to } \\
7.23)\end{array}$ & $\begin{array}{c}7.9 \pm 1.7(7.31 \text { to } \\
8.32)\end{array}$ & $\begin{array}{c}-1.01(-1.2 \text { to }-0.8) \\
p<0.0001\end{array}$ & $\begin{array}{c}5.1 \pm 0.4(4.97 \text { to } \\
5.20)\end{array}$ & $\begin{array}{c}5.1 \pm 0.3(5.01 \text { to } \\
5.20)\end{array}$ & $\begin{array}{c}-0.02(-0.12 \text { to } 0.08) \\
p=0.709\end{array}$ \\
\hline $\mathrm{FRC}_{2.5} \mathrm{~L}$ & $\begin{array}{c}1.9 \pm 0.6(1.73 \text { to } \\
2.09)\end{array}$ & $\begin{array}{c}2.5 \pm 0.9(2.23 \text { to } \\
2.78)\end{array}$ & $\begin{array}{c}-0.6(-0.7 \text { to }-0.5) \\
p<0.0001\end{array}$ & $\begin{array}{c}2.3 \pm 0.8 \\
(2.05-2.55)\end{array}$ & $\begin{array}{c}2.5 \pm 0.9 \\
(2.25-2.84)\end{array}$ & $\begin{array}{c}-0.2(-0.3 \text { to }-0.2), \\
p<0.0001\end{array}$ \\
\hline \multicolumn{7}{|c|}{ 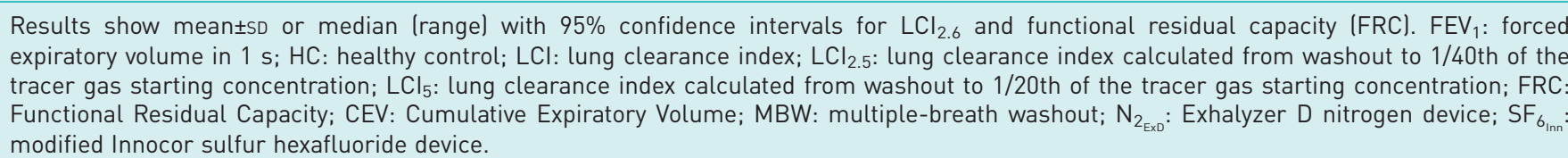 } \\
\hline
\end{tabular}

\section{Discussion}

The primary purpose of this study was to further explore the differences in washout between $\mathrm{N}_{2}$ and $\mathrm{SF}_{6}$. LCI derived from $\mathrm{N}_{2}$ was consistently higher than LCI derived from $\mathrm{SF}_{6}$; and this is the largest LCI difference between $\mathrm{N}_{2}$ and $\mathrm{SF}_{6}$ reported to date, which is probably due to the wide range of age and disease severity in this group of patients, indicating underlying disease pathology. Increased ventilation heterogeneity and potential gas trapping will probably further magnify differences between the two techniques. By viewing the LCI result at an earlier time point $\left(\mathrm{LCI}_{5}\right)$ the discrepancy between gases was
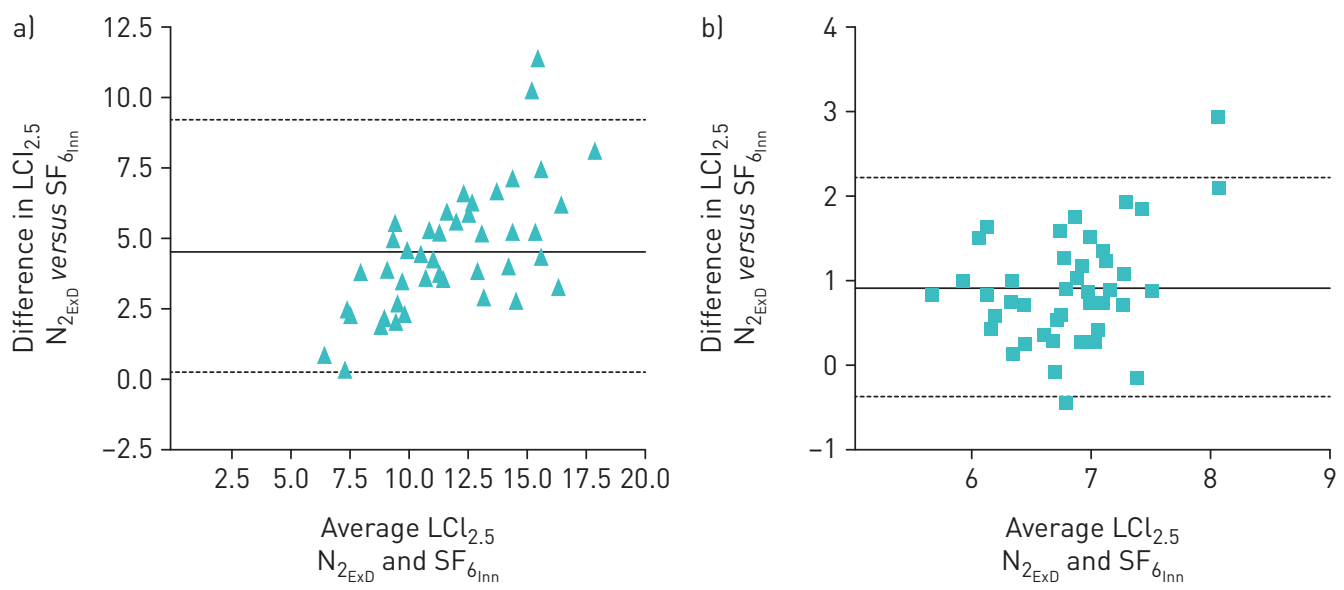

FIGURE 3 Bland-Altman plot of the difference in lung clearance index taken from the traditional end-point of 1/40th of the starting concentration $\left(\mathrm{LCl}_{2.5}\right)$ between Exhalyzer $\mathrm{D}$ (nitrogen $\left(\mathrm{N}_{2_{\mathrm{Ex}} \mathrm{D}}\right)$ ) and Innocor (sulfur hexafluoride $\left(\mathrm{SF}_{\mathrm{I}_{\mathrm{Inn}}}\right)$ ) in a) participants with cystic fibrosis (CF) and b) healthy control (HC) participants. The solid line is the mean difference between devices ( $4.5 \mathrm{in} \mathrm{CF}$ and $0.92 \mathrm{in} \mathrm{HC}$ ) and the dotted lines represent the limits of agreement $(0.08-8.92$ in $\mathrm{CF}$ and $-0.38-2.22$ in $\mathrm{HC}$ ). The difference between devices becomes disproportionately larger with a higher (worse) LCl. 

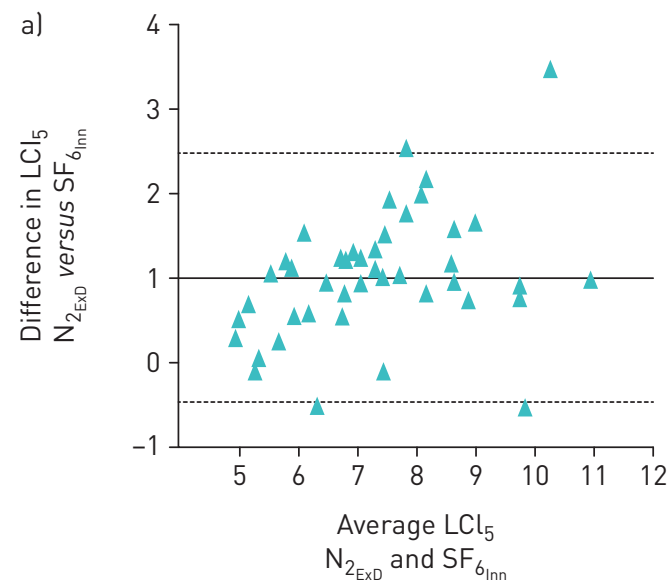

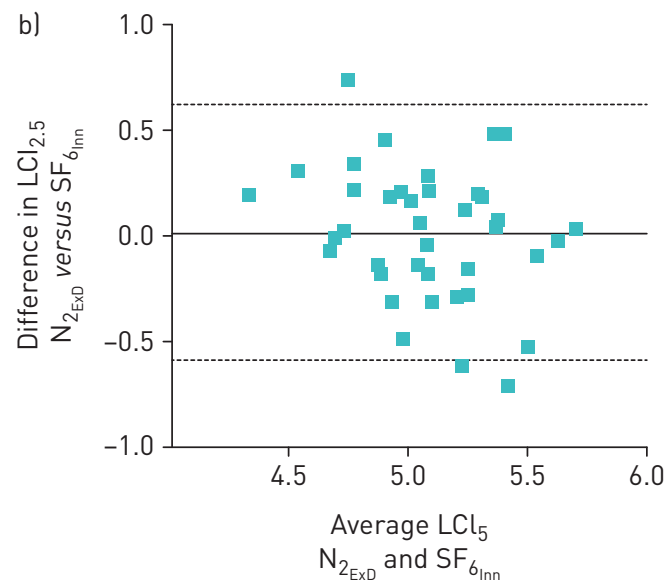

FIGURE 4 Bland-Altman plots of the difference in lung clearance index (LCI) taken from the 1/20th end-point of the starting concentration $\left(\mathrm{LCl}_{5}\right)$ between Exhalyzer $\mathrm{D}$ (nitrogen $\left(\mathrm{N}_{\mathrm{Exx}_{\mathrm{Ex}}}\right)$ ) ExD) and Innocor (sulfur hexafluoride $\left(\mathrm{SF}_{6}\right)$ in a) participants with cystic fibrosis (CF) and b) healthy control $(\mathrm{HC})$ participants. The solid line is the mean difference between devices (1.0 in $\mathrm{CF}$ and 0.01 in $\mathrm{HC}$ ) and the dotted lines represent the limits of agreement $(-0.48-2.49$ in $\mathrm{CF}$ and $-0.59-0.62$ in $\mathrm{HC}$ ). The difference between devices becomes disproportionately larger with a higher (worse) $\mathrm{LCl}$. The difference in $\mathrm{LCl}_{5}$ is not as large as the difference in $\mathrm{LCl}_{2.5}$.

decreased, showing that the impact of the difference was mainly at the tail end of the washout. There are a number of possible explanations for this discrepancy, including inherent tracer and washout gas properties [16], tissue $\mathrm{N}_{2}$ and trapped $\mathrm{N}_{2}$ additionally contributing to the washout trace $[7,8,17]$ and differences between equipment and analysis [18, 19].

Different physical properties of the gases could contribute to differences in washout efficiency [16]. $\mathrm{SF}_{6}$ is a dense gas and will behave differently within the lung to $\mathrm{N}_{2}$. The $\mathrm{N}_{2}$ diffusion front will be more proximally placed within the acinus, which should reduce LCI and shorten $\mathrm{N}_{2}$ washout time [20, 21]. However, comparison of clinical $\mathrm{MBW}$ data derived from helium and $\mathrm{SF}_{6}$, (two gases with even larger differences in molecular weight and hence diffusivity), has not shown discrepancies at anywhere near the same magnitude [22]. Importantly, the effect of gas density on $\mathrm{SF}_{6}$ washout is in the opposite direction to this study when comparing $\mathrm{N}_{2}$ and $\mathrm{SF}_{6}$.

$100 \% \mathrm{O}_{2}$ has been shown to change breathing dynamics and respiratory drive in infants and children [10] and could be problematic in advanced disease, when the respiratory response to hypercarbia may have been blunted [23]. It is unknown when such breathing changes are not relevant, but no change in breathing pattern with $100 \% \mathrm{O}_{2}$ was reported in children age 6-9 years [24]. Hence in the present study, the impact of the washout gas (room air versus $100 \% \mathrm{O}_{2}$ ) on the $\mathrm{N}_{2}$ and $\mathrm{SF}_{6}$ discrepancy is likely to be small.

Poncin et al. [18] completed a comparison of two $\mathrm{N}_{2}$ washout devices and despite both measuring $\mathrm{N}_{2}$, the ExD still took longer to washout to the final end-point. Agreement improved at an earlier time point and

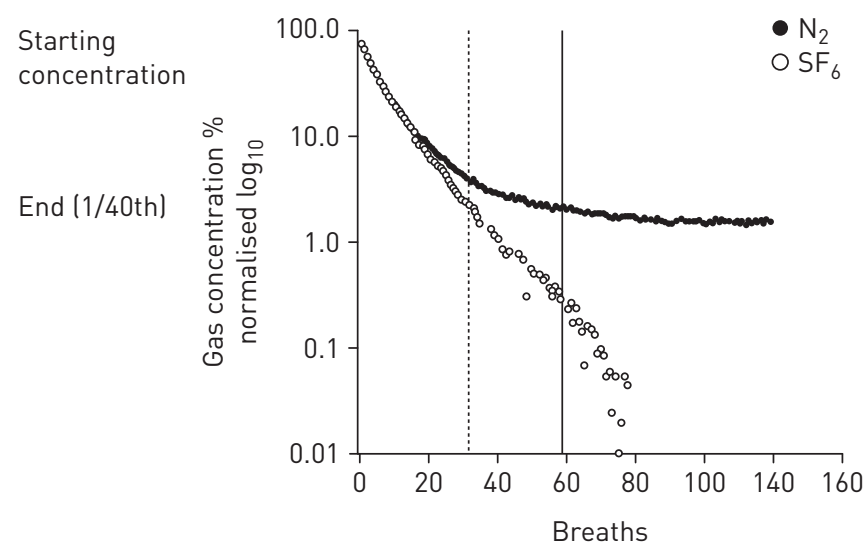

FIGURE 5 Graph of an individual cystic fibrosis patient's gas concentration decline throughout a simultaneous washout of sulphur hexafluoride and nitrogen versus breath number. The gases are displayed in a normalised $\log$ scale for ease of visualisation. The vertical lines (dashed: $\mathrm{SF}_{6}$; solid: $\mathrm{N}_{2}$ ) represent the end-tidal gas concentration at 1/40th of the starting concentration; beyond this point is the extended washout period. 
PONCIN et al. [18] suggest this may be because the algorithm determining nitrogen fractions (washout tracer) could be subject to signal drift and cumulative error over time, which may introduce errors with low nitrogen concentrations. We have also seen that the longevity of the washout, particularly in more severe patients, increases the magnitude of the LCI discrepancy between $\mathrm{SF}_{6}$ and $\mathrm{N}_{2}$.

Only head-to-head data during the same wash-in and washout is likely to definitively assess differences in MBW [25]. Our RMS simultaneous washout eliminated confounding external influences and showed that differences between $\mathrm{N}_{2}$ and $\mathrm{SF}_{6}$ washout still persist, and are therefore not purely artefacts of the indirect gas analysis method.

Our extended washout shows the $\mathrm{N}_{2}$ signal diverging from the $\mathrm{SF}_{6}$ trace and remains persistently elevated if washout continues beyond the conventional termination point (around $1-2 \%$ ), whereas $\mathrm{SF}_{6}$ washes out in a single exponential to reach zero. This may represent the contribution from tissue $\mathrm{N}_{2}$ that is washed out by breathing $100 \% \mathrm{O}_{2}$. NieLSEN et al. [17] modelled a significant impact of increased $\mathrm{N}_{2}$ concentration on the last part of the concentration curve; our clinical observations that technique-related differences are more marked for $\mathrm{LCI}_{2.5}$ than $\mathrm{LCI}_{5}$ support this. NIELSEN et al. [17] suggested that at least $20 \%$ of the measured alveolar $\mathrm{N}_{2}$ signal at the end of washout originated from the blood and tissues rather than the airways, and that the impact would be variable with increasing ventilation heterogeneity and dead space. Tissue $\mathrm{N}_{2}$ contribution may also depend on cardiac output [26], blood volume and $\mathrm{N}_{2}$ tissue stores [8,27].

Estimated $\mathrm{N}_{2}$ release has been calculated from differences between $\mathrm{SF}_{6}$ and $\mathrm{N}_{2} \mathrm{MBW}$ and body plethysmography; a tissue $\mathrm{N}_{2}$ correction attempted to calculate the end-tidal gas concentrations of each washout breath [28] as well as adjusting the final washout end-point according to the washout gas [29]. While correction factors reduce the impact of tissue $\mathrm{N}_{2}$ they do not completely eliminate the effect, so they are not currently recommended [28]. Using a simultaneous washout plus extra in vitro testing, Guglani et al. [26] found what they described as a technical offset error in the $\mathrm{N}_{2_{\mathrm{ExD}}}$. When they further corrected the $\mathrm{N}_{2}$ trace using this offset, $\mathrm{SF}_{6}$ and $\mathrm{N}_{2}$ washouts were similar. This may be an important explanation for some of the equipment differences seen between devices, but manufacturers have not verified the results and the test gases are still not measured directly, unlike with our RMS testing. All of these comparison studies also fail to account for any real physiological differences that may inherently exist between $\mathrm{N}_{2}$ and $\mathrm{SF}_{6}$ washouts [29]; lung model studies would probably help to differentiate technical and physiological factors.

Previous studies have used the same equipment to measure both $\mathrm{SF}_{6}$ and $\mathrm{N}_{2}$ at the same time but calculated $\mathrm{SF}_{6}$ and $\mathrm{N}_{2}$ indirectly (i.e. calculating $\mathrm{N}_{2}$ and $\mathrm{SF}_{6}$ from the measurement of $\mathrm{O}_{2}, \mathrm{CO}_{2}$ and argon). This study used the RMS, the only device that directly measures gas concentrations and therefore could definitively measure both gases at the same time. In the RMS simultaneous washout, $\mathrm{N}_{2}$ still took longer to wash out than $\mathrm{SF}_{6}$. Persistence of these differences in tracer gas washout suggests that the prolonged washout of $\mathrm{N}_{2}$ is at least partially a real phenomenon that both gases are physiologically different to one another and the difference is not simply an artefact of $\mathrm{N}_{2}$ devices. This is particularly true as those with more severe disease and therefore prolonged washouts may be subject to cumulative errors over time.

Using an RMS to simultaneously measure both gases during an MBW has been suggested as a viable method to elucidate gas discrepancies [28]. Our experiences of RMS testing, however, (variability of gas detection, low signal-to-noise ratios) suggest it is an extremely challenging approach. Nitrogen washout requires particular care and calibration as $100 \% \mathrm{O}_{2}$ is viscous and may interfere with the readout capacity of the device. Understanding of differences between washout gases and impact on the device and output is particularly important for more widespread utility of MBW as an outcome measure.

There are some limitations to our study that deserve consideration. Our simultaneous and RMS sections were based on opportunistic numbers and therefore may have introduced a type I error. Despite this we have begun to show that using a correction factor or to ignore any differences between MBW results using different test gases would be inappropriate. For simultaneous testing, only small numbers of participants and only gas concentration and breath data were used (rather than full MBW parameters). The latter was for two reasons: 1) to remove any requirement to match flow volumes and synchronise signals which could have introduced significant errors; and 2) to overcome some differences between software algorithms and calculation of derived signals (since even small software changes have been shown to have a large impact on results [30]). Not all software bias will have been removed (i.e. $\mathrm{C}_{\mathrm{ET}}$ is still calculated slightly differently on each device) but traces were visually inspected to ensure correct selection of the $\mathrm{C}_{\mathrm{ET}}$ using offline software, capable of calculating both $\mathrm{N}_{2}$ and $\mathrm{SF}_{6}$ [31]. Online equipment capable of measuring both $\mathrm{N}_{2}$ and $\mathrm{SF}_{6}$ (Exhalyzer $\mathrm{D}$ version 3.2.1) was not available to the researchers at the time this study was delivered. 
The large dead space in the simultaneous set-up was not ideal, as this may have changed breathing dynamics due to added resistance, although there were no noted changes in tidal volume or respiratory rate (results not shown). The serial placement of the gas sample capillaries for each device may not have been truly simultaneous, but it was a pragmatic compromise to differentiate between equipment while measuring as close as possible to the same time.

As previously highlighted, we had difficulties with the signal quality of RMS testing due to the low $\mathrm{SF}_{6}$ concentrations and the use of $100 \% \mathrm{O}_{2}$. This has been a previous issue with the RMS device, where up to $70 \%$ error was found if synchronisation of flow and gas concentration was not performed and dynamic viscosity was not accounted for [32]. However, by using raw data we have identified averaged end-tidal gas concentrations, even if the signal quality would have been too poor for accurate integration of expired gas volumes, LCI calculation and conclusive RMS results.

We conclude that $\mathrm{N}_{2}$ and $\mathrm{SF}_{6}$ washouts are inherently different; LCIs generated were higher for $\mathrm{N}_{2}$ at the $2.5 \%$ end washout point. We have shown the largest differences to date, exposing software differences and disease severity as further factors to consider when completing an MBW test. Our simultaneous extended washout showed that $\mathrm{N}_{2}$ continues beyond that of $\mathrm{SF}_{6}$ and reaches a nonzero asymptote, probably revealing a contribution of tissue $\mathrm{N}_{2}$ which is additive to the final washout. Our RMS testing, measuring gas concentrations directly, also showed a similar $\mathrm{N}_{2}$ asymptote, suggesting an inherent physiological difference between gases, not just equipment or software bias that may occur between devices. Clinically, $\mathrm{N}_{2}$ results could be interpreted as worse ventilation heterogeneity if previous MBW testing was completed using $\mathrm{SF}_{6} ;$ misinterpretation of data should be avoided.

$\mathrm{SF}_{6}$ and $\mathrm{N}_{2} \mathrm{MBW}$ results are different and should be viewed as such. Future work should focus on the impact of the persistence of the nitrogen signal on minimal clinically important differences.

Acknowledgements: The authors thank the participants and their families at the RBH and Imperial College, RBH Lung Function and Paediatric Respiratory Dept for use of their equipment, and Nicholas Bell (University Hospitals Bristol, Bristol, UK) for use of the SW software. We thank the manufacturers Innovision (Odense, Denmark) and Ecomedics (Durnten, Switzerland) for equipment support. Francois Vermeulen (University Hospital Leuven, Leuven, Belgium) provided generation of ideas.

Support statement: The project was supported by the National Institute for Health Research Respiratory Disease Biomedical Research Unit at the Royal Brompton and Harefield NHS Foundation Trust and Imperial College, London, and sponsored by an unrestricted grant from Novartis. Funding information for this article has been deposited with the Crossref Funder Registry.

Conflict of interest: K.J. Bayfield has nothing to disclose. A. Horsley reports personal fees from pharmaceutical advisory boards during the conduct of the study. E. Alton has nothing to disclose. S. Irving has nothing to disclose. A. Bush has nothing to disclose. J.C. Davies reports grants from the European Cystic Fibrosis Clinical Trials Network and personal fees from pharmaceutical advisory boards, during the conduct of the study.

\section{References}

1 Amin R, Subbarao P, Jabar A, et al. Hypertonic saline improves the LCI in paediatric patients with CF with normal lung function. Thorax 2010; 65: 379-383.

2 Amin R, Subbarao P, Lou W, et al. The effect of dornase alfa on ventilation inhomogeneity in patients with cystic fibrosis. Eur Respir J 2011; 37: 806-812.

3 Davies J, Sheridan H, Bell N, et al. Assessment of clinical response to ivacaftor with lung clearance index in cystic fibrosis patients with a G551D-CFTR mutation and preserved spirometry: a randomised controlled trial. Lancet Respir Med 2013; 1: 630-638.

4 Aurora P, Gustafsson P, Bush A, et al. Multiple breath inert gas washout as a measure of ventilation distribution in children with cystic fibrosis. Thorax 2004; 59: 1068-1073.

5 Yammine S, Singer F, Abbas C, et al. Multiple-breath washout measurements can be significantly shortened in children. Thorax 2013; 68: 586-587.

6 Robinson PD, Latzin P, Verbanck S, et al. Consensus statement for inert gas washout measurement using multiple- and single-breath tests. Eur Respir J 2013; 41: 507-522.

7 Jensen R, Stanojevic S, Gibney K, et al. Multiple-breath nitrogen washout: a feasible alternative to mass spectrometry. PLoS One 2013; 8: e56868.

8 Robinson PD, Latzin P, Ramsey KA, et al. Preschool multiple-breath washout testing. An official American Thoracic Society technical statement. Am J Respir Crit Care Med 2018; 197: e1-e19.

9 Gustafsson PM, Bengtsson L, Lindblad A, et al. The effect of inert gas choice on multiple breath washout in healthy infants: differences in lung function outcomes and breathing pattern. J Appl Physiol 2017; 123: 1545-1554.

10 Sullivan L, Forno E, Pedersen K, et al. Nitrogen back-diffusion during multiple-breath washout with $100 \%$ oxygen. Eur Respir J 2017; 50: 1700679.

11 Horsley AR, Gustafsson PM, Macleod KA, et al. Lung clearance index is a sensitive, repeatable and practical measure of airways disease in adults with cystic fibrosis. Thorax 2008; 63: 135-140.

12 Farrell PM, White TB, Ren CL, et al. Diagnosis of cystic fibrosis: consensus guidelines from the Cystic Fibrosis Foundation. J Pediatr 2017; 181s: S4-S15, e1.

13 Miller MR, Hankinson J, Brusasco V, et al. Standardisation of spirometry. Eur Respir J 2005; 26: 319-338. 
14 Quanjer PH, Stanojevic S, Cole TJ, et al. Multi-ethnic reference values for spirometry for the 3-95-yr age range: the global lung function 2012 equations. Eur Respir J 2012; 40: 1324-1343.

15 Hannon D, Bradley JM, Bradbury I, et al. Shortened lung clearance index is a repeatable and sensitive test in children and adults with cystic fibrosis. BMJ Open Respir Res 2014; 1: e000031.

16 Gustafsson PM. Peripheral airway involvement in CF and asthma compared by inert gas washout. Pediatr Pulmonol 2007; 42: 168-176.

17 Nielsen N, Nielsen JG, Horsley AR. Evaluation of the impact of alveolar nitrogen excretion on indices derived from multiple breath nitrogen washout. PLoS One 2013; 8: e73335.

18 Poncin W, Singer F, Aubriot AS, et al. Agreement between multiple-breath nitrogen washout systems in children and adults. J Cyst Fibros 2017; 16: 258-266.

19 Bell AS, Lawrence PJ, Singh D, et al. Feasibility and challenges of using multiple-breath washout in COPD. Int J Chron Obstruct Pulmon Dis 2018; 13: 2113-2119.

20 Robinson PD, Goldman MD, Gustafsson PM. Inert gas washout: theoretical background and clinical utility in respiratory disease. Respiration 2009; 78: 339-355.

21 Whitfield CA, Jensen OE, Horsley A. P118 differences in molecular diffusivity do not explain discrepancy in lung clearance index measured by nitrogen and SF6 washout. J Cyst Fibros 2018; 17: S92-S93.

22 Gappa SFM. Helium cannot simply be exchanged for SF6 in multiple breath washout. Eur Respir J 2009; 34: Suppl. 53, 204s.

23 Robinson TD, Freiberg DB, Regnis JA, et al. The role of hypoventilation and ventilation-perfusion redistribution in oxygen-induced hypercapnia during acute exacerbations of chronic obstructive pulmonary disease. Am J Respir Crit Care Med 2000; 161: 1524-1529.

24 Jost K, Lenherr N, Singer F, et al. Changes in breathing pattern upon 100\% oxygen in children at early school age. Respir Physiol Neurobiol 2016; 228: 9-15.

25 Vermeulen F, Ophoff J, Proesmans M, et al. Comparison of lung clearance index measured during helium washin and washout in children with cystic fibrosis. Pediatr Pulmonol 2013; 48: 962-969.

26 Guglani L, Kasi A, Starks M, et al. Difference between SF6 and $\mathrm{N}_{2}$ multiple-breath washout kinetics is due to $\mathrm{N}_{2}$ back diffusion and error in $\mathrm{N}_{2}$ offset. J Appl Physiol 2018; 125(4): 1257-1265.

27 Marozkina NV, Gaston B. Nitrogen chemistry and lung physiology. Annu Rev Physiol 2015; 77: 431-452.

28 Kane $\mathrm{M}$, Rayment $\mathrm{JH}$, Jensen $\mathrm{R}$, et al. Correcting for tissue nitrogen excretion in multiple breath washout measurements. PLoS ONE 2017; 12: e0185553.

29 Yammine S, Lenherr N, Nyilas S, et al. Using the same cut-off for sulfur hexafluoride and nitrogen multiple-breath washout may not be appropriate. J Appl Physiol 2015; 119: 1510-1512. jap.00333.2015.

30 Summermatter S, Singer F, Latzin P, et al. Impact of software settings on multiple-breath washout outcomes. PLoS ONE 2015; 10: e0132250.

31 Singer F, Stern G, Thamrin C, et al. Tidal volume single-breath washout of two tracer gases--a practical and promising lung function test. PLoS ONE 2011; 6: e17588.

32 Brunner JX, Wolff G, Cumming G, et al. Accurate measurement of $\mathrm{N}_{2}$ volumes during $\mathrm{N}_{2}$ washout requires dynamic adjustment of delay time. J Appl Physiol 1985; 59: 1008-1012. 